\title{
LAS NEGOCIACIONES DEL ALCA EN PUEBLA, MÉXICO. ALGUNAS REFLEXIONES JURÍDICAS
}

\author{
Jorge WITKER*
}

RESUMEN: Las negociaciones regionales, iniciadas en diciembre de 1994 en la ciudad de Miami, con miras a construir el Área de Libre Comercio de las Américas (ALCA), han entrado en un proceso de estancamiento y parálisis en relación al texto final del tratado, programado para 2005. Este artículo analiza el contexto de las complejidades jurídicas y económicas intervinientes en Latinoamérica (membresías múltiples), resaltando los diversos intereses en juego y proponiendo una agenda de desarrollo que el ALCA debería contemplar para hacer compatible el crecimiento económico con la equidad social, paradigma que se debe acercar más al modelo de la Unión Europea, que al modelo del Tratado de Libre Comercio de América del Norte.

ABSTRACT: The regional negotiations, started on December 1994 in Miami, aiming to build the Free Trade Area of the Americas (FTAA) have brought to a standstill with respect to the final text of the treaty, set for year 2005. This article analyses the context of the legal and economic complexities in Latin American (multiple memberships), underlining the various interests involved and proposing a development agenda that the FTAA shall follow in order to make economic growth compatible with social equity, paradigm which shall approach the European Union's model, more than that of the North America Free Trade Agreement.

RÉSUMÉ: Les négotiations régionaux iniciées en Décembre de 1994 à Miami afin de construir la Zone de Libre Echange des Amériques (ALCA) se trouvent dans un moment d'impasse et de suspention en ce qui concerne le texte du traité, programmé pour l'année 2005. Cet article analyse le contexte des complexités juridiques et économiques intervenantes dans l'Amérique Latine, tout en faisant ressortir les plusieurs intérêts en jeu et en proposant une agenda de développement que l'ALCA devrait prendre en considération pour rendre compatible l'acroissement économique et l'équité sociale. C'est un paradigma que doit se rapprocher plus au modèle de l'Union Européenne qu'à celui de NAFTA.

* Investigador del Instituto de Investigaciones Jurídicas y profesor titular de derecho económico de la UNAM. 
SUMARIO: I. Introducción. II. Variables socio-jurídicas del ALCA. III. Marco jurídico-institucional. IV. Dinámica de los temas en negociación. V. ALCA y una agenda del desarrollo.

\section{INTRODUCCIÓN}

El Área de Libre Comercio de las Américas ha entrado a la etapa final de las negociaciones sin que la sociedad regional asuma con propiedad la profundidad de los compromisos que tal empresa supone, y que se presenta en un contexto histórico de reflujo y parálisis de la tendencia globalizadora de corte neoliberal. El último fracaso de la Organización Mundial de Comercio en Cancún, México, es un referente que gravitará con fuerza en las negociaciones del ALCA. ${ }^{1}$

Con todo, el ALCA debe abordarse analíticamente en un triple escenario espacial. Esto es, sus disciplinas actuarán a nivel local, nacional y regional-internacional.

El estancamiento de la economía estadounidense, como centro dinámico de la globalización mundial, es un signo que puede impactar la negociación del ALCA en dos sentidos. Como amenaza a los sectores proteccionistas del propio congreso estadounidense y como un pretexto legítimo de países como Argentina, Brasil, Ecuador y Venezuela para no abrir sus mercados, especialmente agrícolas, a la competencia regional, opción ésta que ya se materializó en la frustrada Junta Ministerial de la OMC de septiembre último.

El presente artículo pretende encuadrar el contexto negociador del ALCA en variables socio-jurídicas regionales, plantear aspectos jurídicos vigentes en las membresías múltiples de los países latinoamericanos, analizar brevemente los temas en negociación, para luego resaltar algunos efectos, no deseables, en materia de derechos económicos y sociales que se han presentado en la experiencia mexicana, a diez años de vigencia del Tratado de Libre Comercio de América del Norte (TLCAN). ${ }^{2}$

1 Como saldo positivo, sin embargo, hay que destacar la creación del Grupo de los 21, que desde 1976 no se expresaba a nivel tricontinental; con Brasil, India, China y otros.

2 Evaluación realizada por el Senado de la República Mexicana plasmada en dos tomos (México, 2000). 


\section{VARIABLES SOCIO-JURÍDICAS DEL ALCA}

La América del siglo veintiuno está caracterizada por una opinión pública demandante, actuante y participativa. El protagonismo de los actores sociales y la toma de conciencia de los agentes económicos constituye un factor estratégico que, directa o indirectamente, debe impactar las negociaciones finales del ALCA.

Por ello, es cada vez más intensa la presencia y participación creciente, a través de múltiples intereses de actores no estatales, en la elaboración de políticas hacia la región: agricultores y fabricantes, empresas comerciales, trabajadores, consumidores, grupos ecologistas, defensores de los derechos humanos y de las libertades civiles, así como instituciones, fundaciones y medios de comunicación, entre otras, que compiten por afectar las políticas en un contexto pragmático y fácilmente permeable. ${ }^{3}$

Otro aspecto a considerar es el referente a la necesaria decodificación de los contenidos de los nueve temas que conforman la agenda negociadora del ALCA. En efecto, temas como acceso a mercados, agricultura, servicios, inversiones, compras gubernamentales, propiedad intelectual, resolución de controversias, dumping y subvenciones, y política de competencia, pasan por interrogantes profundas ya que comprometen las políticas públicas de desarrollo de treinta y tantos países latinoamericanos.

Dicha decodificación afecta a la sociedad civil con interrogantes cómo: ¿Qué negocian? ¿Con qué autoridad negocian? ¿A quienes representan? ¿Donde rinden cuentas? ¿Qué tipo de empresas fueron consultadas? ¿Qué reglas de origen se evaluaron sectorialmente? ¿Cuáles reservas regionales se pactan en materia de compras gubernamentales? ¿Regulaciones estatales en materia de patentes para fármacos y medicamentos de salud pública? ¿Límites a la inversión especulativa y promoción a la inversión productiva creadora de empleos y nuevas tecnología? ¿Qué materias pueden asumir carácter plurilateral y otras de perfil multilateral? ${ }^{4}$

3 Otro mundo es posible, Santiago de Chile, Le Monde Diplomatique-Editorial "Aún Creemos en los Sueños", 2001.

4 Ortega Riquelme, Eugenio, La globalización en la encrucijada, Santiago de Chile, LOM, 2002. 
Las respuestas a éstas y otras interrogantes es lo que denominamos decodificar el contenido de las negociaciones que tienen lugar en estos meses en las negociaciones de Puebla, México.

Lo anterior es una tarea trascendente, pues los discursos oficiales intentan despejar dudas y suspicacias a través de un discurso dual y ambiguo. Por una parte, afirman que el ALCA es un simple tratado de libre comercio, al cual no se le puede exigir otra cosa que facilitar el libre flujo de intercambio de bienes y servicios. Así, temas como pobreza, educación y empleo no son negocio para las corporaciones internacionales y la educación y la salud, sólo importan si son objeto de inversiones para servicios y compras gubernamentales. Por otra parte, dichos temas deben ser competencia de los gobiernos a los cuales se les priva — vía rebajas tributarias aduaneras - de los recursos para abordar la marginación y el desempleo. Al respecto, se hace interesante resaltar la decisión del gobierno de Chile, de compensar los menores ingresos aduaneros, que le significará el tratado bilateral de libre comercio con Estados Unidos de América, con una alza del 18 a 19\% del impuesto al valor agregado, aplicado a todos los consumidores de dicho país. Un buen ejemplo de populismo financiero para apoyar a los empresarios chilenos.

Un tercer elemento, complementario de los anteriores, es lo que algunos negociadores califican como "preparar a la región para el libre comercio hemisférico".

En efecto, para algunos funcionarios y analistas, la suscripción de tratados de libre comercio es un ejercicio que se autolegitima per se, de tal suerte que el libre comercio tiene como consecuencias el crecimiento económico y el progreso en los niveles de vida. Por ello, otros se preguntan ¿habrá tiempo histórico para esperar los frutos del libre comercio y dejar, a nuestras sociedades, en manos de las fuerzas del libre mercado? ¿No tendrán los países más desarrollados la obligación o el deber de establecer en el contexto del ALCA, una agenda social mínima, con fondos compensatorios de ayuda para, precisamente, preparar a la región para ejercer y practicar el libre comercio en términos más simétricos y equitativos? ¿No sería esta última una estrategia realmente viable para emparejar el campo de juego a los agentes económicos locales? ${ }^{5}$

5 El Banco Mundial comienza a reconocer los excesos del Consenso de Washington, y ya cuestiona las privatizaciones dogmáticas para los países en desarrollo. 


\section{MARCO JURÍDICO INSTITUCIONAL}

El mosaico de estándares jurídicos de los integrantes de la futura ALCA nos enfrenta ha diversas hipótesis.

Por ejemplo ¿Centroamérica negociará como Estados miembros o como Estados partes del Mercado Común Centroamericano? El Mercado Común del Sur, integrado por cuatro repúblicas: Argentina, Brasil, Paraguay y Uruguay, ¿negociará como bloque o como Estados partes? Respecto a los países integrantes del TLCAN, si bien pueden hacerlo como países independientes, pues no hay autoridad supranacional que los represente, deberán cuidar la operatividad de la cláusula de nación más favorecida, de tal suerte que los compromisos del ALCA sean compatibles con los compromisos del TLCAN.

Lo anterior supone definir un dato sobre la identidad política de los integrantes de la futura ALCA, en el sentido de aceptar qué agrupaciones o bloques subregionales existentes se ubican más en la tesitura de asociaciones o agrupaciones intergubernamentales sin órganos supranacionales o supraestatales al estilo de la Unión Europea.

Otra variable a considerar es la membresía de cada país en la Organización Mundial de Comercio, en donde aún subsisten elementos discriminatorios favorables a los países en desarrollo, contemplados en las cartas del GATT 47 y 94. Aquí habrá que evaluar la incorporación del ALCA a las disciplinas del artículo XXIV del GATT y tipificar el carácter jurídico del ALCA en relación a los cuatro momentos; zona de libre comercio, unión aduanera, mercado común y unión económica, allí contemplados. ${ }^{6}$

Así, de las membresías múltiples que los países latinoamericanos ostentan, plantean interrogantes jurídicas complejas. En efecto, todos los bloques regionales vigentes (TLCAN-Mercosur-CAN, Aladi, Caricom, etcétera) actúan bajo las normas del artículo XXIV del Acuerdo General sobre Aranceles Aduaneros y Comercio, el que a su vez permite una variedad de hipótesis, a saber: a) Zona de libre comercio o unión aduanera constituida según el artículo XXIV GATT; $b$ ) Acuerdo interino orientado a la formación de una unión aduanera o zona de libre comercio según el artículo XXIV GATT, y c) Una zona preferencial entre países en desa-

6 Himmer, Waldemar y Prager, Diezmar, GATT, Aladi Y NAFTA, Buenos Aires, Ciudad Argentina, 1998, p. 92. 
rrollo con base en la "cláusula de habilitación", contemplada en el propio artículo XXIV (Comercio Sur-Sur).

Estas tres hipótesis, que están presentes en la región, deben conjugarse con el principio de la cláusula de nación más favorecida, lo sustancial o esencial del comercio recíproco regional, y complementariamente con la extensión amplia o limitada de las liberaciones arancelarias. Esto es, aplicando la cláusula de nación más favorecida "hacia dentro o hacia fuera de los bloques interalca".

Respecto a los socios del Norte, las interrogantes al respecto no son menores. Por ejemplo, ¿Estados Unidos de América seguirá planteando la posición de que el libre comercio no tienen nada que ver con las relaciones laborales ni con la protección ambiental? Igualmente, ¿seguirá ALCA considerándose en el derecho estadounidense como un acuerdo congresional en donde la ley de implementación reserva al congreso de dicho país la última palabra en materia de obligaciones específicas respecto de los 33 países restantes de la región? Por otra parte, como lo establece la autorización de promoción comercial (TPA) del congreso al Ejecutivo, ¿habrá también otro fondo de diez mil o más millones de dólares para la eventual pérdida de empleos que experimenten los países de la región con ocasión de la desgravación arancelaria y eventual cierre de empresas que un ALCA asimétrica y excluyente puede ocasionar?

Finalmente y como corolario jurídico institucional y dada la diferencia estructural que existe, entre los derechos latinoamericanos de raíz románica y de perfil monista en el derecho internacional vigente, y los derechos anglosajones de cuño judicial y heteroaplicativos (Implementation $A C T$ ) ALCA debería tipificar su entidad e identidad, esto es, tipificarse en función de la orientación de sus disciplinas o de las eventuales decisiones que formule directamente.

Así, ALCA al ser un ente de cooperación o integración podría asumir diversas connotaciones: a) Acuerdo macro que diseña parámetros y principios; b) Cláusulas programáticas que definen objetivos de mediano y largo plazo; c) Cláusulas pragmáticas que definen contenidos inmediatos como las desgravaciones arancelarias pactadas, funcionamiento de fondos financieros específicos (agricultores, Pymes, etcétera), procedimientos de consultas para conciliar y arbitrar conflictos, etcétera. ${ }^{7}$ 
Por último, con los elementos precedentes habría que definir el tipo de institución u organismo que asumiría el ALCA ¿organismo supranacional $\mathrm{u}$ organismo intergubernamental?

En efecto, si ALCA llegará a estructurarse como organización supranacional — posibilidad que podría darse sólo a nivel latinoamericanolos Estados miembros pueden delegar en la organización creada por el acuerdo de preferencias la facultad de consensar tratados preferenciales o de conceder unilateralmente beneficios a terceros Estados.

En cambio, si ALCA se crea como nueva organización intergubernamental — posibilidad cierta, pues Estados Unidos de América por principio y tradición jurídica rechaza todo indicio de supranacionalidad- los países miembros del acuerdo conservan sus potestades soberanas en sus relaciones con terceros Estados, pudiendo cada cual conceder ventajas o preferencias a terceros, lógicamente respetando el techo que cada país tenga en el contexto de la Organización Mundial de Comercio. ${ }^{8}$

Con todo, y dada la experiencia unipolar practicada por Estados Unidos de América, tanto en el Consejo de Seguridad de Naciones Unidas (Irak), como en la 5a. Junta ministerial de la OMC (México), el destino legal del ALCA se vislumbra como de simple cooperación y de carácter intergubernamental.

En efecto, el marco institucional diseñado en el capítulo XXI del proyecto ALCA establece un marco institucional de perfiles intergubernamentales al crear el consejo, conformado por los ministros de comercio de cada parte, un Comité Ejecutivo, integrado por los viceministros o subsecretarios de comercio; los comités y finalmente la Secretaría del ALCA.

El consejo tendrá las siguientes funciones:

a) Evaluar periódicamente la aplicación y los resultados del acuerdo.

b) Conocer de cualquier otro asunto que pudiese afectar el funcionamiento del acuerdo.

c) Modificar el cumplimiento de los objetivos del acuerdo: los planos de eliminación arancelaria, las reglas de origen del capítulo XX de carácter específico, los anexos sobre inversión y servicio y compras de gobierno.

8 Cretella, Neto José, Direito Processual Na Organização Mundial do Comercio, Río de Janeiro, De Forense, 2003, p. 53. 
Por su parte, el Comité Ejecutivo reemplaza las funciones del consejo durante los intervalos y vela por el cumplimiento y aplicación de las disposiciones del acuerdo, supervisando el funcionamiento de la secretaría y proveyendo de información administrativa, contable y financiera al consejo.

Los comités son órganos relacionados a los capítulos y funcionarán para aclarar y despejar dudas respecto a los objetivos específicos de su competencia y están subordinados en cuanto a normas de procedimiento al Comité Ejecutivo.

Un Comité Consultivo de la Sociedad es una novedad que muchos no esperaban, pero que al formar parte del marco institucional abre perspectivas a la participación de empresarios, sindicatos, las ONG y organizaciones sociales y/o instituciones académicas. ${ }^{9}$

También el Órgano de Solución de Controversias, integrado por todas las parte del Comité Ejecutivo, y con carácter permanente, tiene a su cargo administrar las dos instancias creadas al respecto: Grupo Neutral o Panel (primera instancia) y Órgano de Apelación (segunda instancia).

\section{DINÁMICA DE LOS TEMAS EN NEGOCIACIÓN}

Los temas en negociación se inscriben en un contexto de negociaciones Norte-Sur, que como veremos no sólo contemplan los llamados "temas de frontera" - acceso a mercado y libre flujo de mercancías - sino aspectos que inciden en la organización económica interna de los países, y en general en la forma de hacer negocios (inversión, servicios, propiedad intelectual, compras gubernamentales).

Antes de describir someramente la Agenda del ALCA, es necesario traer a cuenta los principios y condiciones originales que orientan las negociaciones y que antes de la Junta Ministerial de Miami (noviembre de 2003) parecían inamovibles. En efecto, cabe mencionar los siguientes:

a) Las decisiones serán tomadas por consenso, no por mayorías; $b$ ) Sólo se tomarán acuerdos cuando todos los puntos de la agenda sean consensuados; c) La cobertura de producto será del 85\% de los productos hoy comercializados entre los países participantes; d) El ALCA podrá coexistir con acuerdos subregionales de la misma generación; e) Los

9 Parte de la presión de las protestas de las ONG y de los grupos "globalifóbicos" responde a la creación del Comité Consultivo de la Sociedad en ALCA. 
acuerdos serán congruentes con las reglas de la Organización Mundial de Comercio; f) Todos los derechos y obligaciones deberán ser cumplidos por todos los países participantes.

Estos condicionantes evidencian que cada país es soberano al decidir adherirse al ALCA y que dicha aceptación deberá ser total y no parcial ni segmentada. Sin embargo, la Junta de Miami atemperó, en parte, estos principios y, gracias a la posición de Brasil, se incorporaron perfiles de gradualidad y parcialidad, aceptándose que para los temas sensibles de implicaciones en las políticas públicas, se aceptarán los acuerdos plurilaterales, en coexistencia con las multilaterales regidas por el principio single undertaking.

La complejidad de estas negociaciones deriva de las asimetrías existentes entre los treinta y cuatro países participantes, ejemplos al respecto: los valores de los PIB conjuntos del 2000 (TLCAN, 11 trillones de dólares; Caricom, 28 billones; Mercado Común Centroamericano, 56 billones; Comunidad Andina, 277 billones; Mercosur, 842 billones). ${ }^{10}$

Otra diferencia a resaltar lo evidencia la disponibilidad de carga tributaria aduanera en los ingresos totales de los países miembros. Así, en el Mercosur, el porcentaje es de 6; en la Comunidad Andina, de 9\%; en el Mercado Común Centroamericano, alcanza 19\%; y en el Caricom cercano al $44 \%{ }^{11}$

Los temas de la agenda se inician con el acceso a mercados de las mercancías que en un $85 \%$ se negocian en la región americana. Aquí se trata de acordar desgravación arancelaria en plazos preestablecidos y que deben comenzar de los actuales niveles tarifarios en donde a nueva cuenta las disparidades emergen. Así las tarifas medias de Estados Unidos de América, Canadá y México no superan el 4\%, aunque existen importantes rubros protegidos por "picos arancelarios" que para algunos productos llegan hasta el 300\%. En cambio, América Latina, con excepción de Chile y México, la tasa media arancelaria es superior al $18 \%{ }^{12}$

Pero en este acceso al mercado, las barreras no arancelarias (normas, restricciones, reglas de origen, antidumping, reglamentos de mercados, subsidios, etcétera) constituyen prácticas proteccionistas frecuentes no

10 Baumann, Renato, "ALCA-comercio interlatinoamericano: oposición o complementariedad", en varios autores, $A L C A$, un debate sobre la integración, México, UNAM, 2004, p. 262.

11 Ibidem, p. 262.

12 Cohen, T., Global Political Economy. Theory and Practice, Nueva York, Longman, 2000, p. 276. 
erradicadas por las disciplinas multilaterales. Al respecto, la experiencia de México en productos como atún, azúcar, aguacate, cemento y otros, revela que los tratados de libre comercio funcionan parcialmente, según sean los intereses en juego.

En cuanto a los productos agrícolas, la vigencia de cuantiosos subsidios imposibilita una competencia leal para los productores regionales, los que además deben soportar la ausencia de apoyos tecnológicos, innovación de semillas y fertilizantes, y una comercialización ineficiente y costosa. Este tema es toral para países como Argentina, Brasil, Colombia y el propio México, que ha experimentado un efecto dual de consecuencias moderadas en materia de producción de granos, marginación y desempleo. Aquí se hace indispensable considerar fondos compensatorios y programas de extensión agrícola integrados, que tengan como referente, una autosuficiencia alimentaria mínima, centrada en los propios mercados nacionales y consumos autóctonos. ${ }^{13}$

Otro aspecto sensible en el acceso a mercados de mercancías está referido a la reglas de origen en donde los productores regionales deben pugnar por establecer compromisos de valor agregado y contenido regional para calificar el origen de las mercancías. El generalizado método del salto arancelario, tan defendido por los ensambladores y maquiladores corporativos, no es un factor que coadyuva al desarrollo industrial regional, pues privilegia la mano de obra como único insumo a utilizar sin efectos en el resto de las cadenas productivas nacionales o regionales. Este factor, en la actualidad, con la potente presencia de China, no facilita exportaciones basadas exclusivamente en la mano de obra barata. ${ }^{14}$

En esta misma vertiente de intercambios de mercancías, las prácticas impositivas de medidas antidumping, no han merecido especial atención de parte de los socios mayores. Sería recomendable acordar criterios más objetivos que superen la arbitrariedad con que países desarrollados protegen sus mercados internos desalentando las producciones eficientes, como se ha demostrado en productos como acero, textiles y otros, afectando a países como México y Brasil. Al respecto, en las negociaciones

13 Calva, José Luis, México, más allá del neoliberalismo, México, Plaza y Janes, 2000.

14 Witker, Jorge, Las reglas de origen en los tratados de libre comercio, Chile, Lexi-Nexis, 
del ALCA se está orientando tan sensible vertiente a los mecanismos establecidos en la Organización Mundial de Comercio. ${ }^{15}$

Respecto a los temas sensibles que van más allá del acceso a mercados de mercancías, las negociaciones se están abocando a lo que algunos autores denominan "el núcleo duro" de las negociaciones. ${ }^{16}$

Este núcleo duro lo constituyen inversiones, servicios, derecho de la propiedad intelectual, mecanismos de solución de controversias, reglas de comercio (antidumping, salvaguardias, medidas compensatorias), comercio electrónico, política de competencia y compras gubernamentales, cláusula laboral y medio ambiente. ${ }^{17}$

Las siguientes reflexiones están orientadas a suministrar una panorámica general de estos temas y su relación con lo que se ha dado en llamar, la agenda del desarrollo latinoamericano. ${ }^{18}$

Conviene señalar que respecto a estos estratégicos asuntos, existen en la región dos percepciones: los que buscan una negociación del tipo OMC-like y otros que prefieren una agenda NAFTA-like, según sea la profundidad de los compromisos por asumir. ${ }^{19}$

\section{Inversiones}

Como es sabido, el comercio internacional contemporáneo, se finca en mercancías, servicios e inversiones, de lo cual deriva que los temas de fronteras (aranceles, barreras no arancelarias, normas de salud y fitosanitarias, etcétera) carecen de eficacia, si no se vinculan a inversiones, reglas de origen, propiedad intelectual, servicios financieros y otros.

Por ello, la inversión y los inversionistas constituyen factores estratégicos que reclaman en el ALCA un tratamiento de full protection and security y libertad máxima a sus actividades. Por su parte, la agenda del desarrollo, si bien comparte la presencia de las inversiones como coadyuvante del crecimiento económico regional, no percibe tan favorablemente

15 Smith, Cintia Pussetto, "La política comercial de Estados Unidos. Una contradicción entre comercio libre y comercio justo", Comercio Exterior, México, vol. 53, núm. 3, 2003, p. 271.

16 Isaacs, A., "Trade Promotion Authority: A Fast Track to Further Harm?, 2002, http://www. adaction. org./.

17 Idem.

18 Witker, Jorge, "La agenda social del ALCA", en varios autores, Hacia un nuevo derecho del trabajo, México, UNAM, 2003, p. 57.

19 Gruben, W., "Was NAFTA behind Mexico's high maquila growth?", Economic and Financial Review, Federal Reserve Bank of Dallas Texas, 3er. trimestre de 2001, 2001. 
esa libertad reclamada en los diversos foros mundiales, como OMC y OCDE, incluyendo el frustrado Acuerdo Multilateral de Inversiones (AMI). ${ }^{20}$

En el ALCA, el tema no ha logrado los consensos esperados. Así Estados Unidos de América y Canadá postulan que las reglas de inversiones deberían contener no sólo inversiones directas, sino también indirectas o de portafolio. A esa posición se oponen varios países (Brasil, Argentina) que sostienen que dichas reglas deberán restringirse a las inversiones extranjeras directas (IED).

Adicionalmente, en lo que hay consenso es que el ALCA debe garantizar la certidumbre jurídicas a las inversiones directas, a las cuales debe tratarse con transparencia y legalidad en materia de expropiaciones, repatriaciones, requisitos de desempeño, trato nacional y de nación más favorecida, mecanismos de solución de controversias, aspectos todos contemplados tanto en el TLCAN como en el TLC-EUA-Chile de reciente aprobación. ${ }^{21}$

\section{Servicios}

El capítulo de servicios representa otra tensión entre la "agenda del desarrollo" y el interés de los países exportadores de servicios (Estados Unidos de América y Canadá). Cabe señalar que la participación de los servicios en el PIB, en la región, supera el $60 \%$, lo que evidencia la alta significación de dicho sector en la economía regional. ${ }^{22}$

Dos han sido los tópicos discutidos en las negociaciones sobre servicios: a) La inclusión o exclusión de los mismos en listas positivas y negativas. Los países latinoamericanos en general prefieren negociar listas positivas de servicios, mientras Canadá y Estados Unidos de América proponen listas negativas; b) Respecto a la observancia en ALCA del Acuerdo GATS (Acuerdo sobre Servicios de la OMC), un grupo de países acepta la metodología de los cuatro módulos de prestación de servicios: transfronterizos; prestación de servicios en el exterior; presen-

20 Helleiner, Eric, "From Bretton Wood to Global Finance: A World Turnes upside down", en Stubbs, Richard Yunderhill y Geoffrey R. D. (eds.), Political Economy and the changing Global Order, Londres, MacMillan, 1994.

21 Véase el capítulo XI del TLCAN y el capítulo X del Tratado Bilateral Chile-Estados Unidos de América.

22 Sennes, Ricardo et al., "El ALCA en el marco de la nueva economía", en varios autores, ALCA, un debate sobre la integración, México, UNAM, 2003, p. 322. 
cia comercial y movimientos temporales, sea incorporado al capítulo respectivo. ${ }^{23}$

En cambio, para Estados Unidos de América, México, Chile y los países caribeños, defienden que la presencia comercial en servicios, sea tratada en el capítulo de inversiones, sujeta a las normas de protección total y libertad de capital. ${ }^{24}$

El capítulo se completa con regulaciones en materias de telecomunicaciones y servicios financieros, superando las disciplinas convenidas en el TLCAN. ${ }^{25}$

\section{Derecho de la propiedad intelectual}

La propiedad intelectual, que abarca propiedad industrial y derechos de autor, adquiere en la era del conocimiento el carácter de insumo estratégico para las economías regionales.

El ALCA, en este capítulo, se articula a los tratados de París-Berna, el ADPIC de la OMC y el capítulo XVII del TLCAN. Bajo estas disciplinas se reiteran tres principios fundamentales: trato nacional, trato de nación más favorecida y transparencia.

Como es lógico, frente a la protección de la propiedad intelectual, hay dos percepciones que derivan de precedentes de la propia OMC. Para los países desarrollados ésta protección se encamina a resguardar la inversión económica de empresas, sin consideración de orden público o social alguno. ${ }^{26}$

Afortunadamente, el proyecto de capítulo del ALCA armoniza y atenúa tal pragmática afirmación y al respecto señala en el artículo 2.1: "La protección y observancia de los derechos de propiedad intelectual que contempla el presente capítulo deberán contribuir a la promoción de la innovación tecnológica y a la transferencia y difusión de la tecnología en las Américas, en beneficio recíproco de los productores y de los usuarios

23 Ibidem, p. 324.

24 Los servicios y las inversiones son aspectos que deben regularse conjuntamente, pues en el TLCAN los servicios de transporte terrestre internacional de carga no son permitidos a México por Estados Unidos de América y, en cambio, exige libre inversión para crear empresas de transporte totalmente estadounideses para cubrir carga interna mexicana.

25 El ALCA constituye una mayor apertura en telecomunicaciones que lo contemplado en el TLCAN.

26 Orozco Contreras, Marcela, "Propiedad intelectual", en varios autores, Resultados del Tratado de Libre Comercio de América del Norte en México, México, Red Mexicana de Acción frente al Libre Comercio, 2001, p. 123. 
de conocimientos tecnológicos con el fin de favorecer el bienestar social y económico, y el equilibrio de derechos y obligaciones".

Este precepto, unido a la transferencia de tecnología en favor de los países en desarrollo, indica un leve avance respecto al capítulo XVII del TLCAN. Adicionalmente, los nombres de dominio, las denominaciones de origen, los derechos conexos, la cláusula moral en las patentes, conocimiento tradicional y acceso a los recursos genéticos, modelos de utilidad, regulación de variedades vegetales advierten independientemente de los "corchetes" del tercer borrador, que las negociaciones van por buen camino, por lo menos a nivel del texto formal del proyecto de tratado del ALCA. ${ }^{27}$

\section{Mecanismos de solución de controversias}

Este capítulo está referido a los probables conflictos y controversias que se presenten al interpretar o aplicar las disposiciones del tratado, en el territorio de cada uno de los treinta y cuatro estados partes del ALCA. Así, cuando una parte considere que una medida vigente, o en proyecto de la otra parte, es o podría ser incompatible con las obligaciones del ALCA y pudiere causar anulación o menoscabo de los beneficios que se pudo haber esperado recibir de su aplicación, tiene derecho a activar los mecanismos del capítulo.

Bajo el principio de cooperación, no es aceptable tomar medidas o represalias sin consultas, a menos que se hayan agotado las disciplinas prescritas en el capítulo.

Las consultas, los casos de urgencia y la creación de grupos neutrales, las listas de árbitros, la aceptación del Código de Conducta y Reglas de Procedimiento son aspectos que desarrolla el capítulo.

El marco institucional bajo la tuición de la Secretaría del ALCA, lo compone un órgano ejecutivo de solución de controversias y un órgano de apelación.

Finalmente, en materias en que las partes contendientes estimen que son competentes los órganos de la Organización Mundial de Comercio, elegido dicho foro, no habrá posibilidad de activar estos mecanismos

27 Becerra Ramírez, Manuel, "Las nuevas normas sobre PI en el continente americano. Comentarios al proyecto sobre propiedad intelectual del ALCA", en varios autores, op. cit., nota 22, p. 175. 
convenidos en el capítulo XXIII del ALCA que precedentemente hemos resumido. ${ }^{28}$

\section{Política de competencia}

El proyecto del capítulo XIX del ALCA está referido a disciplinas que eviten o sancionen las prácticas anticompetitivas, tanto de empresas estatales como de agentes privados.

La competencia y concurrencia son factores que inciden y se conectan con otros capítulos como inversión y compras de gobierno, de tal suerte que sin evitar y prevenir las prácticas anticompetitivas, las desregulaciones y aperturas tendrían efectos negativos en los mercados.

En efecto, los comportamientos anticompetitivos que se contemplan son, además de los monopolios estatales designados legalmente que deben actuar con criterios de racionalidad económica privada, acuerdos entre competidores con efectos sobre los precios, los abusos de empresas o grupos de empresas con función de dominio en un mercado relevante y las concentraciones, fusiones o adquisiciones de efectos anticompetitivos que afecten la eficiencia económica y el bienestar del consumidor.

Los principios básicos que perfilan este proyecto de capítulo: transparencia, derecho de audiencia, protección a la confidencialidad y cooperación entre los gobiernos, constituyen los consensos de los futuros miembros del ALCA, los que deben actualizar y emitir leyes nacionales de competencia funcionales a estos principios convenidos en ALCA. ${ }^{29}$

Finalmente, conviene destacar que las tesis de Canadá y Chile para disciplinar las prácticas desleales junto a las prácticas restrictivas, a nivel de la legislación interna de cada país, no han prosperado en ALCA, que ha seguido el esquema segmentado de separarlas en capítulos distintos, pese a responder ambos al concepto genérico de prácticas anticompetitivas con efectos extraterritoriales. ${ }^{30}$

28 Cruz Miramontes Rodolfo, El TLC: controversias, soluciones y otros temas conexos, México, McGraw Hill, 1997.

29 Witker Jorge, El derecho de la competencia económica en el TLCAN, México, UNAM-Porrúa, 2003.

30 Idem. 
6. Reglas de comercio (antidumping, salvaguardias y medidas compensatorias)

Una de las barreras no arancelarias más frecuentes en el comercio internacional actual lo conforman las prácticas desleales de dumping y subvenciones, y el uso y abuso de medidas de salvaguardias. ${ }^{31}$

En cuanto a la práctica de dumping, el capítulo no ofrece elementos nuevos respecto al Acuerdo Antidumping de la OMC. Por otra parte, Estados Unidos de América ha reiterado que en dicha regulación del ALCA no puede modificar su actual legislación, que como sabemos deriva de la sección 731 de la Ley de Comercio de 1930. ${ }^{32}$

Las medidas compensatorias se refieren a sobretasas arancelarias que gravan importaciones que han recibido subsidios o subvenciones en sus países de origen. Aquí el capítulo reenvía al Acuerdo sobre Subvenciones y Derechos Compensatorios de la OMC, sin tampoco promover cambios significativos a nivel regional.

Las medidas de salvaguardias se contemplan en un capítulo especial (capítulo XIV), y constituyen también sobretasas arancelarias y/o restricciones cuantitativas que se aplican a importaciones súbitas e imprevistas que, por su volumen o cantidad, provocan un daño grave o amenaza de daño grave a una rama de la producción del país de destino. Se contemplan salvaguardias provisionales por sectores específicos y las globales, que pueden ser reguladas por el Acuerdo de Salvaguardias de la OMC. ${ }^{33}$

\section{Compras gubernamentales}

Las compras de gobierno se ha percibido como un instrumento utilizado por diversos países como estímulo a los productores nacionales en sectores prioritarios. Desde la creación de la OMC, los países industrializados han pugnado por remover esta restricción y abrir dicho mercado a la competencia internacional.

En el ALCA, a nueva cuenta, se presenta esta demanda, aunque los socios mayores mantienen en sus propios mercados severas limitantes. Brasil tiene una Ley Federal que establece reservas básicas para los pro-

31 Barbosa, Antonio, Barreiras aos produtos, serviços e investimentos do Brasil nos Estados Unidos, São Paulo, Edições Aduaneiras LTDA, 2002, p. 76.

32 Idem.

33 Idem. 
ductos brasileños, y Estados Unidos de América regula dicho sector con tres leyes plenamente vigentes, pese al capítulo X del TLCAN: Buy American, Balance of Payment Programa and Small Bussiness Act. Estas leyes privilegian a las empresas pequeñas y medianas, permitiendo autonomía a los órganos licitantes, con lo cual anulan las prescripciones convenidas en los tratados internacionales. ${ }^{34}$

Aquí se observan reservas de todo tipo y los consensos se ven lejanos por la contradicción de intereses y el impacto social de una apertura repentina y no gradual. Como integrante del núcleo duro de problemas del ALCA, lo más probable es que este capítulo sea calificado como un acuerdo plurilateral en que no todos suscriben en su totalidad su contenido.

\section{Comercio electrónico}

La utilización y el desarrollo de las tecnologías de la información y las comunicaciones ha propiciado un cambio importante en el ámbito comercial, al redefinir la dicotomía tradicional de comercio nacional e internacional. Hoy se habla de un comercio electrónico, digital o virtual. Así la reducción del tiempo y disminución de la distancia han dinamizado los mercados y cambiado la cultura empresarial en todos los aspectos. ${ }^{35}$

El ALCA no es ajena a estos procesos, por cuanto los capítulos comercio transfronterizo de servicios y el área de los servicios financieros, exigen que la región establezca criterios jurídicos mínimos al respecto.

Se trata de facilitar el comercio electrónico, sin reglamentaciones burocráticas, al suministro electrónico de servicios ni tributos aduaneros, bajo principios de no discriminación para los productos digitales.

La cooperación en materia de compartir información y experiencia sobre leyes, regulaciones y programas en el comercio electrónico es una intención declarada en el ALCA, máxime que el TLC-Estados Unidos de América-Chile ya contempla en el capítulo quince esta materia estratégica para el comercio globalizador del presente. ${ }^{36}$

34 Baumann, Renato, op. cit., nota 10, p. 269.

35 Rico Carrillo, Mariliana, Comercio electrónico, Internet y derecho, Venezuela, Legis, 2003, pp. 43 y ss.

36 Idem. 


\section{ALCA Y UNA AGENDA DEL DESARROLLO}

El sentido y complejidad de los temas brevemente descritos, obligan a evaluar este proyecto de integración hemisférica en un contexto superador de los simples flujos de comercio e inversiones. Es necesario, y con base en la experiencia del TLCAN, plantear una visión de conjunto, sin prejuicios, con el fin de ver con antelación los posibles efectos intro y extra hemisféricos. ${ }^{37}$

Hay consenso en que el estándar predominante en Latinoamérica se encuadra en un regionalismo abierto, que se expresa en diversos acuerdos y bloques comerciales subregionales. ${ }^{38}$

La constante en todos ellos, con la excepción del TLCAN, es que enfatizan las disciplinas en los temas de fronteras, oscilando entre zonas de libre comercio incumplidas y uniones aduaneras imperfectas. ${ }^{39}$

El TLCAN es el primer instrumento mercantil trilateral que al integrar negociaciones Norte-Sur instituye disciplinas que arduamente todavía se discuten en la Organización Mundial de Comercio. Se trata del 1lamado núcleo duro que, como vimos más arriba, articula y profundiza compromisos no fáciles de cumplir, especialmente en países latinoamericanos, en que el Estado sigue jugando un papel estratégico en el desarrollo regional. ${ }^{40}$

En efecto, el ALCA es un desafío, más allá de los impactos geoeconómicos y geopolíticos, al estilo de desarrollo regional. En otras palabras, el ALCA, como posibilidad y riesgo, obliga, en el contexto del regionalismo abierto, a la definición o redefinición de los modelos de desarrollo latinoamericanos, por sustitución de importaciones y desarrollismo nacional, que estuvieron vigentes hasta la década de los ochenta. Así el papel del Estado como inductor del desarrollo, los márgenes de políticas industriales sustentadas, en parte, en las compras de gobierno y las

37 En lo intro, hay que evaluar el impacto real de acceso al mercado estadounidense; en lo extra, los compromisos de la región (Chile, México, Mercosur, etcétera) con la Unión Europea.

38 Oropeza, Arturo, México-Mercosur. Un nuevo diálogo para la integración, México, UNAM, 2002.

39 Idem.

40 Estos temas y el incumplimiento de los países desarrollados acerca de lo convenido en Doha: eliminar los subsidios agrícolas, fueron los causantees del fracaso de la Ronda Multilateral de Negociaciones de Cancún, México, 2003. 
protecciones gubernamentales a las pequeñas y medianas empresas, son aspectos sobre los cuales el ALCA tendrá repercusiones significativas. ${ }^{41}$

Por ello, es fundamental que en el horizonte del regionalismo abierto vigente en el continente, los países puedan elaborar una agenda de desarrollo mínima, que sin proteccionismos aberrantes, equilibre los costos-beneficio de un ALCA que, armonizando los indicadores socio-económicos-asimétricos de sus miembros, coadyuve a crear los empleos y empresas que nuestras sociedades reclaman con vehemencia.

Una agenda del desarrollo económico-social mínimo debería contener algunos de los puntos que a continuación mencionamos:

1. Acceso fluido y estable para los productos regionales al mayor mercado del planeta.

2. Fomento y certidumbre jurídicas para las inversiones extranjeras directas.

3. Reserva de políticas públicas para fomentar educación, ciencia y tecnología para la región.

4. Plantear listas exclusivas en materia de desregulación y liberación de los servicios, y evitar que las asimetrías tecnológicas aumenten el desempleo en la región.

5. Reservar los sectores agrícolas a los productores nacionales, mientras los países del Norte no eliminen los subsidios a sus producciones agropecuarias.

6. Defender los recursos naturales de explotaciones irracionales que atenten contra el medio ambiente.

7. Crear un espacio específico de negociación para el tratamiento de los temas laborales y sociales, en especial, la observancia de todos los instrumentos internacionales referidos a derechos humanos, que incluya a los derechos económicos y sociales.

8. Adopción de la cláusula social que obliga a los Estados parte a respetar y cumplir las normas fundamentales de la Organización Internacional del Trabajo (OIT).

9. Adopción de medidas para garantizar que los países tengan las autonomías y el derecho de regular el flujo de capital especulativo, y de ésta forma proteger sus economías contra la inestabilidad financiera. 
10. Realización de negociaciones graduales y flexibles de la liberalización comercial, con plazos más largos para las economías en desarrollo y más pobres.

11. Eliminación en los acuerdos de cualquier limitación y/o condicionamiento a la implantación de políticas de desarrollo nacionales y a la adopción de legislaciones que permitan a los países proteger (temporal o definitivamente) sus áreas más sensibles (principalmente en los capítulos sobre inversiones, liberación de servicios, propiedad intelectual); acceso a patentes y propiedad intelectual en las áreas básicas para la implantación de servicios esenciales a la población (salud, energía, agricultura, etcétera), y plazos mayores en la limitación de patentes para los países de menor desarrollo.

12. Garantizar a los Estados nacionales la adopción de mecanismos y normas que regulen la conducta empresarial para proteger los intereses económicos y sociales.

13. Creación de mecanismos jurídicos de protección ambiental que impidan la acción destructiva de los grandes grupos económicos en detrimento del medio ambiente.

En consecuencia, el ALCA debiera replantear los esquemas centrados en forma exclusiva en el libre comercio y proponer enfoques más amplios que sin desconocer los logros de la interdependencia productiva y tecnológica, se inserten en proyectos nacionales que fomenten el desarrollo económico con empleo, y que ubiquen el respeto y vigencia de los derechos económicos y sociales en contextos de sujetos de la globalización y no de meros objetos, reflejos de una globalidad ajena e impuesta por los centros del poder mundial. ${ }^{42}$

42 Véase CEPAL, La Inversión Extranjera en América Latina y el Caribe (LC/G2123-P), Santiago de Chile, enero de 2001. 